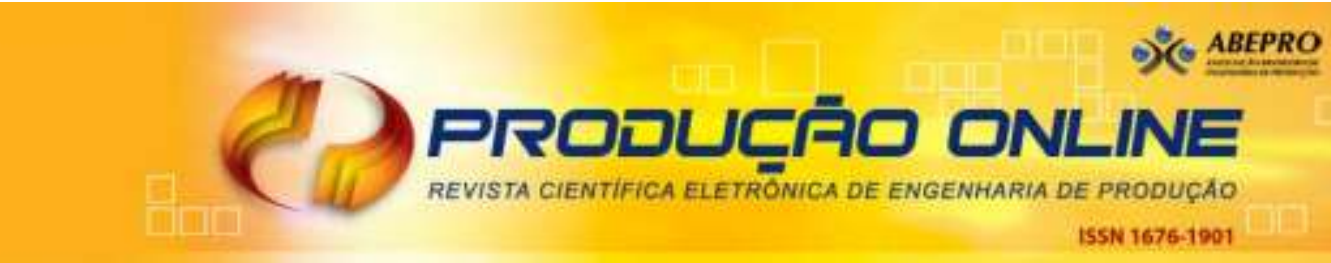

\title{
GESTÃO VERDE DA CADEIA DE SUPRIMENTOS: ANÁLISE DA PRODUÇÃO ACADÊMICA BRASILEIRA
}

\section{GREEN SUPPLY CHAIN MANAGEMENT: ANALYSIS OF BRAZILIAN ACADEMIC PUBLICATIONS}

\author{
José Carlos Barbieri* E-mail: jose.barbieri@fgv.br \\ José Milton de Sousa Filho**E-mail: miltonsousa@unifor.br \\ Cristiane N. Brandão* E-mail: cristiane.brandao@gmail.com \\ Luiz Carlos Di Serio* E-mail: luiz.diserio@fgv.br \\ Edgar Reyes Junior ${ }^{* *} E$-mail: edgarreyes2000@yahoo.com.br \\ *Escola de Administração de Empresas de São Paulo (EAESP)/Fundação Getúlio Vargas (FGV), SP \\ ${ }^{* *}$ Universidade de Fortaleza (UNIFOR), Fortaleza, CE \\ ***Universidade Federal de Roraima (UFRR), Boa Vista, RR
}

Resumo: Este artigo trata da temática ambiental sob a perspectiva da Gestão da Cadeia de Suprimentos. Com a incorporação de preocupações ambientais de modo sistemático na gestão da cadeia de suprimento, tem-se o que se denomina Gestão da Cadeia de Suprimento Ambiental ou Gestão Verde da Cadeia de Suprimentos (Green Supply Chain Management - GSCM), como é denominado com mais frequência. O assunto GSCM interessa não só aos acadêmicos, mas também ao público profissional, principalmente no que concerne às novas obrigações legais, pressões sociais e de stakeholders de diversos tipos, e questões relacionadas à competitividade das empresas e das suas cadeias de suprimento. No entanto, não se sabe ao certo como esse conhecimento vem sendo produzido no Brasil, daí a necessidade de realizar um mapeamento de quais áreas e subáreas da GSCM vêm sendo estudadas com maior frequência. Desta forma, o presente trabalho pode ser caracterizado como uma desk research e tem por objetivo analisar a produção acadêmica brasileira sobre o tema gestão verde da cadeia de suprimentos. Como delimitação do escopo da pesquisa, foram coletados artigos relacionados ao tema publicados de 2006 a 2010 em congressos brasileiros das áreas de Administração e Engenharia de Produção; foram eles: EnANPAD, SIMPOI e SIMPEP. Foram coletados e analisados 110 artigos, e observou-se como principais resultados que a área de Operações Verdes representa $81 \%$ dos artigos publicados e destes $45 \%$ enfocam Logística Reversa; do total, $70 \%$ dos artigos são empíricos, destes $77 \%$ utilizaram abordagem qualitativa e $57 \%$ do total são estudos de caso.

Palavras-chave: Gestão Verde da Cadeia de Suprimentos. Cadeia de Suprimentos. Gestão Ambiental.

Abstract: This paper deals with environmental issues from the perspective of Supply Chain Management. With the incorporation of environmental concerns in a systematic manner the concept of Green Supply Chain Management (GSCM) has emerged. The subject GSCM interests not only to academics but also to professional audience especially with regard to new legal obligations, and social pressures of various types of stakeholders, as well as issues related to the competitiveness of enterprises and their supply chains. However, the way in which this knowledge is being produced in Brazil is not clear, hence the need for a mapping which areas and sub-areas of GSCM has been studied most frequently. Thus, this work can be characterized as a desk research that aims to analyze the Brazilian academic publications on green supply chain management. In order to delimit the scope of the research, we collected articles published from 2006 to 2010 in specific Brazilian congresses of Management and Production Engineering, as EnANPAD, SIMPOI and SIMPEP. 110 papers were 
collected and analyzed.The area of Green Operations represents $81 \%$ of published articles and $45 \%$ of these focus on Reverse Logistics. $70 \%$ of total papers are empirical and $77 \%$ use a qualitative approach, while $57 \%$ of the total are case studies.

Keywords: Green Supply Chain Management. Supply Chain. Environmental Management.

\section{INTRODUÇÃO}

Este artigo trata da temática ambiental sob a perspectiva da Gestão da Cadeia de Suprimentos, também conhecida como Gestão Verde da Cadeia de Suprimentos (Green Supply Chain Management) ou Gestão Cadeia de Suprimentos Sustentável (Sustainable Supply Chain Management). Cadeia de suprimentos (supply chain) pode ser entendida como um conjunto de três ou mais organizações ou indivíduos diretamente envolvidos nos fluxos de produtos, serviços, recursos financeiros e informações da fonte ao consumidor (MENTZER et al., 2001, p. 4). Lambert et al. (1998, p. 504) definem cadeia de suprimento como o "alinhamento de firmas para levar produtos ao mercado". Essa cadeia engloba todos os estágios envolvidos direta ou indiretamente no atendimento de um pedido de um cliente, como fornecedores, fabricantes, transportadores, armazenadores, distribuidores, varejistas e o próprio cliente, bem como prestadores de assistência técnica e qualquer outro que represente etapas do processo de produção e comercialização de produtos e serviços (CHOPRA; MEINDL, 2003, p. 3). Desse modo, por gestão da cadeia de suprimento (supply chain management - SCM) entende-se as atividades voltadas para interligar essas etapas para alcançar resultados desejados.

Lambert et al. (1998, p. 504) definem SCM como "a integração de processos de negócio desde os usuários finais até os fornecedores originais que provêem produtos, serviços e informações que adicionam valor aos consumidores". Corrêa (2010, p. 15), de forma semelhante, define SCM como a "administração integrada dos processos principais de negócios envolvidos com fluxos físicos, financeiros e de informações, englobando desde os produtores originais de insumos básicos até o consumidor final [...] de forma a agregar valor para os grupos de interesse legítimos e relevantes para a rede". Para Mentzer et al. (2001, p. 18), é "a coordenação sistêmica e estratégica das funções tradicionais dos negócios e das táticas através dessas funções em uma empresa particular e através dos negócios com a cadeia de suprimento com o objetivo de melhorar o desempenho no longo prazo das empresas 
individuais e da cadeia de suprimento como um todo". Para a consecução desse objetivo, a SCM se vale de diversos processos de gestão, como gestão do relacionamento com clientes e fornecedores, gestão da demanda e dos fluxos de manufatura, gestão dos retornos, entre outros (LAMBERT et al., 1998).

Com a incorporação de preocupações ambientais de modo sistemático na gestão da cadeia de suprimento, tem-se o que se denomina Gestão da Cadeia de Suprimento Ambiental ou Gestão Verde da Cadeia de Suprimentos (Green Supply Chain Management - GSCM), como é denominado com mais frequência. Conforme Srivastava (2007), a GSCM integra o pensamento ambiental com o da gestão da cadeia de suprimento convencional, tais como projeto de produtos, seleção de materiais e de fornecedores, processos produtivos, entrega de produtos finais aos consumidores e gestão do fim da vida útil dos produtos.

Numa perspectiva internacional, a GSCM vem sendo estudada a partir de diferentes metodologias, setores da indústria e abordagens (SRIVASTAVA, 2007), contudo, numa perspectiva brasileira, ainda não existe um mapeamento dos estudos sobre GSCM que aborde todos os artigos publicados em congressos da área num determinado período de tempo. Levando em consideração que tal assunto é emergente e tem ganhado importância na área de gestão de operações, e que cada vez mais artigos sobre o tema vêm sendo publicados nos principais periódicos internacionais da área, faz sentido entender melhor a produção acadêmica brasileira sobre o tema.

O assunto GSCM interessa não só aos acadêmicos, mas também ao público profissional, principalmente no que concerne às novas obrigações legais, pressões sociais e de stakeholders de diversos tipos, e questões relacionadas à competitividade das empresas e das suas cadeias de suprimento. Esta última questão, já discutida em outros estudos, tais como Sharma e Vredenburg (1998), Hart (1995) e Porter e van der Linde (1995), faz com que profissionais busquem maior conhecimento sobre GSCM no intuito de gerar maior competitividade à empresa, e parte desse conhecimento vem sendo produzida no ambiente acadêmico. No entanto, não se sabe ao certo como esse conhecimento vem sendo produzido no Brasil, daí a necessidade de realizar um mapeamento de quais áreas e subáreas da GSCM vêm sendo pesquisadas com maior frequência (logística 
reversa, reciclagem, remanufatura, ecoeficiência, avaliação do ciclo de vida, produção mais limpa etc.), quais metodologias de pesquisa vêm sendo utilizadas e em quais setores da economia (têxtil, metalúrgico, madeireiro, papel e celulose etc.) são realizados os estudos. Além disso, até o momento, a área de GSCM no Brasil, por não possuir uma agenda própria de pesquisa, tem ficado condicionada aos esforços individuais de pesquisadores espalhados pelo país.

Desta forma, o presente artigo intenciona contribuir com conhecimento no campo da GSCM, dispondo do seguinte objetivo geral de pesquisa: analisar a produção acadêmica brasileira sobre o tema Gestão Verde da Cadeia de Suprimentos. No intuito de alcançar plenamente esse objetivo geral, fazem-se necessários os seguintes objetivos específicos:

- Delimitar adequadamente o escopo da coleta de dados, visando coletar uma quantidade significativa de artigos no âmbito da gestão verde da cadeia de suprimentos;

- Categorizar os artigos em subáreas no âmbito da gestão verde da cadeia de suprimentos;

- Verificar as abordagens, os setores e os aspectos metodológicos utilizados nos artigos pesquisados.

Buscando delimitar o campo de pesquisa, optou-se por analisar os artigos publicados nos principais congressos brasileiros da área de Administração e Engenharia de Produção, já que esta segunda tem grande influência sobre as publicações nas áreas de SCM e GSCM e de Gestão Operações. Desta forma, foram coletados os artigos publicados nos anais de cinco anos (2006-2010) do Encontro da Associação Nacional de Pós-Graduação e Pesquisa em Administração (EnANPAD), Simpósio de Administração da Produção, Logística e Operações Internacionais (SIMPOI) e Simpósio de Engenharia de Produção (SIMPEP), que tratavam de forma geral sobre o tema GSCM. A opção por artigos publicados em anais de eventos científicos deve-se ao fato de que são mais abundantes do que os artigos publicados em revistas acadêmicas. Além disso, os trabalhos apresentados nesses eventos refletem com mais intensidade o interesse dos acadêmicos em 
temas emergentes, devido ao tempo mais curto entre a submissão e a avaliação do artigo.

Outra delimitação do campo de pesquisa concerne ao tema geral tratado, a GSCM, que não raro é confundido com Gestão da Cadeia de Suprimento Sustentável (Sustainable Supply Chain Management - SSCM). A SSCM integra as práticas coerentes das dimensões da sustentabilidade com as da gestão da cadeia de suprimento convencional. De acordo com Seuring e Müller (2008), a SSCM refere-se à gestão dos fluxos de materiais, informações e capital, assim como a cooperação entre empresas da cadeia de suprimento para alcançar as três dimensões do desenvolvimento sustentável, a saber: as dimensões econômica, social e ambiental, levando-se em conta as necessidades dos consumidores e das partes interessadas. Na GSCM estão presentes a dimensão econômica e a ambiental de forma explícita, mas não a social. Preocupações com o nível de emprego, a educação dos funcionários, o desenvolvimento das comunidades vizinhas aos estabelecimentos da cadeia de suprimento, a proteção aos grupos vulneráveis e outras relacionadas com a dimensão social não são objeto desta análise. Assim, o presente trabalho é sobre GSCM, e não sobre SSCM.

Este artigo está subdivido em seis partes, iniciando por esta introdução. A segunda parte trata da discussão teórica sobre gestão verde da cadeia de suprimentos em seus diversos aspectos, inclusive mencionando teorias que abordam a sustentabilidade na cadeia de suprimentos; a terceira parte apresenta o método utilizado nesta pesquisa, abordando sua execução, coleta e análise dos dados. A quarta parte trata dos resultados da pesquisa e discussão; por fim, a quinta e última parte trata das considerações finais, principalmente no que diz respeito às limitações do estudo e sugestões de pesquisas futuras.

\section{DISCUSSÃO TEÓRICA}

A inclusão da temática ambiental no âmbito da gestão de operações tem sido explorada em diversos artigos (ANGELL; KLASSEN, 1999; JIMÉNEZ; LORENTE, 2001; KLEINDORFER; SINGHAL; WASSENHOVE, 2005; LINTON; KLASSEN; JAYARAMAN, 2007; JACOBS; SINGHAL; SUBRAMANIAN, 2010; WU; PAGELL, 
2011; SILVA; PIMENTA; CAMPOS, 2013) e pouco a pouco tem ampliado sua participação na agenda de pesquisa internacional da área de operações. Conforme argumentam Kleindorfer, Singhal e Wassenhove (2005), os pesquisadores da área de gestão de operações enfrentam o desafio de inserir questões relacionadas ao meio ambiente em suas áreas tradicionais de estudo. Tais desafios advêm das pressões institucionais, governamentais e da sociedade civil em consequência dos impactos ambientais e poluição, dentre outros aspectos, causados pelas empresas. Aspectos considerados graves, como o aquecimento global, também colaboram ampliando o desafio das empresas no que diz respeito à inserção de questões ambientais em sua cadeia de suprimentos.

A gestão verde da cadeia de suprimentos tem raízes tanto na gestão ambiental como na gestão da cadeia de suprimentos (SRIVASTAVA, 2007). Trabalhos que envolvem as áreas de gestão ambiental e estratégia (PORTER; VAN DER LINDE, 1995), por exemplo, já apontaram os impactos que a cadeia de valor e a rede de suprimentos podem gerar ao meio ambiente. Da mesma forma, é proeminente a preocupação de alguns pesquisadores de operações com a sustentabilidade (ANGELL; KLASSEN, 1999), sob o argumento de que outras áreas de gestão já partiram na frente em relação a tal preocupação (marketing, estratégia etc.), bem como a necessidade de maiores estudos para um amplo entendimento sobre operações sustentáveis.

Ao tratar da transição entre cadeia de suprimentos convencional e cadeia de suprimentos verde, outras questões relevantes observadas na literatura são desenvolvimento de produto (MAGNAGO; AGUIAR; PAULA, 2012) e a análise do ciclo de vida (ACV) (HANSEN; SEO; KULAY, 2010). O conceito de ACV é essencial para a cadeia verde, pois envolve todas as etapas de um produto ou serviço, desde a extração da matéria-prima até a disposição final do produto (CARVALHO; BARBIERI, 2010). O ciclo de vida de um produto pode ser observado na Figura 1, onde é mostrado o percurso conhecido como "do berço ao túmulo", pois inicia com a extração do recurso natural e termina na disposição final, passando, quando possível, por processos de reúso e reciclagem.

Figura 1 - Ciclo de vida do produto 


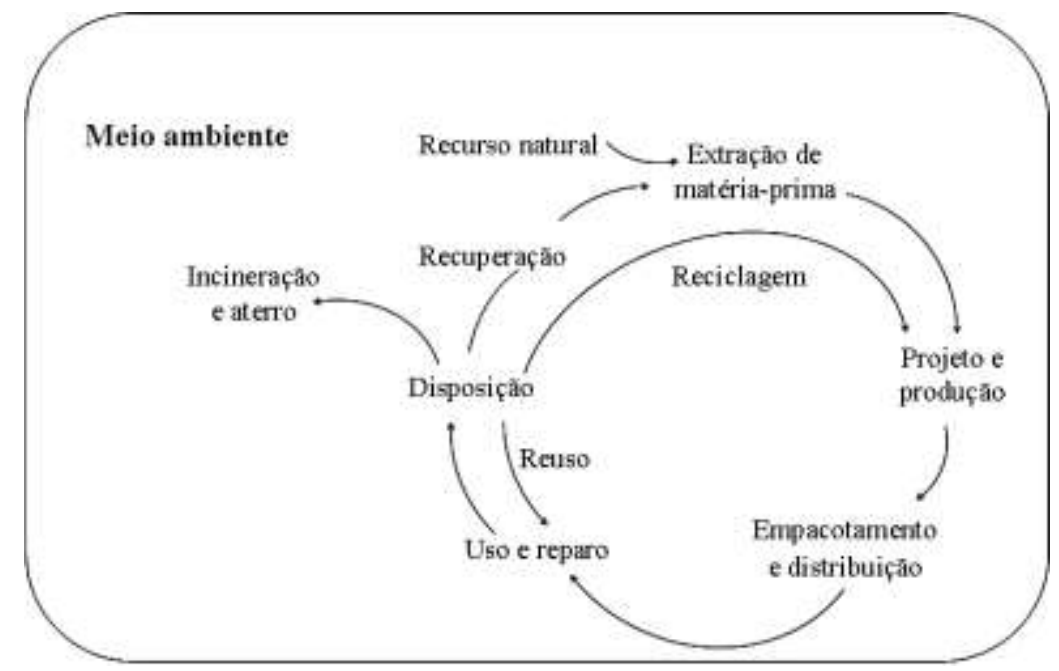

Fonte: Adaptado de United Nations Environmental Program (2007)

Sob o ponto de vista da evolução teórica, o tema gestão verde da cadeia de suprimentos tem sido estudado com diferentes métodos de pesquisa e sob diferentes enfoques, ora avaliando a relação entre fornecedores e a empresa focal, ora buscando analisar a cadeia completa, levando em consideração os fornecedores, a empresa focal e os compradores. Além disso, estudos teóricos (LINTON; KLASSEN; JAYARAMAN, 2007) e desk research (KLEINDORFER; SINGHAL; WASSENHOVE, 2005; SRIVASTAVA, 2007) têm sido publicados em periódicos da área de operações, traçando um panorama sobre o tema num determinado momento. Tal variedade de estudos tem gerado diferentes resultados e insights que tornam necessárias novas pesquisas para aprofundar o conhecimento sobre o tema e evoluir as questões que estão sendo discutidas.

O trabalho de Klassen e Vachon (2003), por exemplo, abordou o tema a partir de uma abordagem quantitativa enfocando como a colaboração e a avaliação na cadeia de suprimentos poderia melhorar os indicadores de gestão ambiental da empresa focal. Como resultados da survey com 202 empresas, os autores observaram que existe relação entre as atividades de colaboração com os fornecedores e o nível de investimento em gestão ambiental, bem como existe relação entre as atividades de avaliação com clientes e o nível de investimento em gestão ambiental.

Ainda numa abordagem quantitativa, o trabalho de Testa e Iraldo (2010) objetivou avaliar os fatores determinantes e motivações da implementação da 
gestão verde da cadeia de suprimentos em 4.188 empresas industriais de sete países. Utilizando um modelo econométrico para mensurar que fatores determinam a implantação da cadeia de suprimentos verde, os autores obtiveram achados como: (a) a existência de um sistema de gestão ambiental é fator determinante para a adoção de uma cadeia de suprimentos verde; (b) a adoção de uma cadeia de suprimentos verde reduz consideravelmente o impacto ambiental das operações da empresa; (c) a relação entre desempenho ambiental e financeiro é inconclusiva e ambígua, segundo os resultados estatísticos; dentre outros achados.

Numa perspectiva qualitativa, Pagell e Wu (2009) pesquisaram o tema a partir de dez estudos de caso qualitativos, técnica pouco utilizada na área de operações em âmbito internacional. Como resultados, os autores apresentam sete proposições teóricas que podem ser utilizadas em estudos futuros. Dentre as proposições, podem ser citadas, por exemplo, que (a) a capacidade de inovação é necessária para construir uma cadeia de suprimentos verde; e (b) uma gestão positivamente orientada à sustentabilidade é necessária para construir uma cadeia de suprimentos verde. Tais achados são relevantes para a evolução teórica do campo.

O estudo da cadeia de suprimentos sob a ótica da sustentabilidade também ocorre em indústrias específicas, como no trabalho de Matos e Hall (2007) que abordou de forma qualitativa dois casos, um no setor de petróleo e gás, e outro no setor de biotecnologia na agricultura, tendo como foco de análise a avaliação do ciclo de vida. Para o estudo dos casos e análise dos dados foi utilizada a grounded theory, e como resultado foi proposto um framework que ajuda a analisar o fenômeno a partir da teoria da complexidade, da teoria dos stakeholders, da gestão de riscos e da dinâmica da inovação.

Os estudos de Klassen e Vachon (2003), Matos e Hall (2007), Pagell e Wu (2009) e Testa e Iraldo (2010) são bons exemplos da variedade de perspectivas utilizadas no que diz respeito aos estudos empíricos em GSCM. Apesar do mainstream da área de operações em âmbito internacional ser claramente quantitativo, a existência de exemplos de estudos qualitativos em GSCM demonstra o caráter neófito e exploratório desse campo de estudo.

Numa outra perspectiva, artigos teóricos, desk research e proposições de agendas de pesquisa também têm sido apreciados pelos periódicos internacionais. 
O trabalho de Gold, Seuring e Beske (2010), por exemplo, apresenta uma revisão de literatura sobre cadeia de suprimentos sustentável e recursos interorganizacionais, sob o argumento de que essa relação tem o potencial de gerar e sustentar vantagens competitivas interfirmas através da colaboração na cadeia em torno de questões sociais e ambientais. Como modelo de análise para o argumento, os autores utilizam a resource-based view e a relational view.

Por outro lado, trabalhos que enfocam a proposição de agenda de pesquisa para GSCM também já foram publicados em âmbito internacional, como o artigo de Angell e Klassen (1999). Na ocasião, os autores argumentaram que as questões ambientais são importantes no contexto atual e precisavam ser incluídas no mainstream da área de operações. A partir disso, foi sugerida uma agenda de pesquisa internacional no que diz respeito à inclusão dos aspectos ambientais na área de operações, e dentre as sugestões estavam tópicos relacionados a: instalações industriais e meio ambiente; tecnologia de processos; capacidades; integração vertical e redes de fornecedores; gestão da qualidade, dentre outros.

No Brasil, o trabalho de Gonçalves-Dias et al. (2009) buscou comparar as publicações (periódicos e congressos) nacionais e internacionais sobre sustentabilidade na cadeia de suprimentos, em que foram analisados 61 artigos. Tratou-se de uma desk research e teve como resultados o mapeamento e a apresentação de um quadro analítico baseado nos artigos coletados. Dentre as áreas contempladas no estudo, foi dado um grande enfoque à logística reversa em detrimento de outros temas constantes da GSCM, contudo essa é uma questão de delimitação e escopo, necessários em qualquer trabalho acadêmico.

Muitos outros estudos poderiam ser citados (JIMÉNEZ; LORENTE, 2001; JACOBS; SINGHAL; SUBRAMANIAN, 2010; VENDRAMETTO et al., 2010; WU; PAGELL, 2011; SELLITTO et al., 2013), e, como se pode perceber, a variedade de estudos enfocando as diferentes perspectivas da GSCM torna o campo de estudo fértil e rico em possibilidades de novas contribuições e avanços. Contudo, faz-se necessário entender como a construção desse conhecimento vem se configurando no Brasil e quais são as lacunas existentes. Para esse tipo de estudo, trabalhos como Angell e Klassen (1999) e Srivastava (2007) são benchmarkings valiosos que 
ajudam a montar uma estrutura de análise que possibilita pesquisar a produção acadêmica brasileira sobre o tema Gestão Verde da Cadeia de Suprimentos.

\section{MÉTODO}

A presente pesquisa pode ser caracterizada como uma desk research, ou seja, baseou-se em dados secundários e visou coletar e analisar artigos cuja temática geral tratava da GSCM. No total foram analisados 110 artigos publicados entre os anos de 2006 e 2010 nos anais dos seguintes congressos: Encontro da Associação Nacional de Pós-Graduação e Pesquisa em Administração (EnANPAD), Simpósio de Administração da Produção, Logística e Operações Internacionais (SIMPOI) e Simpósio de Engenharia de Produção (SIMPEP). Neste momento tornase importante fazer a seguinte ressalva: o Encontro Nacional de Engenharia de Produção (ENEGEP), importante congresso da área, não pôde ser acessado na época da coleta de dados, assim os presentes pesquisadores não puderam analisar os artigos publicados nos anais desse evento. A impossibilidade de coletar e analisar os artigos apresentados no ENEGEP é considerada uma limitação do presente estudo.

A coleta dos artigos foi direcionada por um conjunto de palavras-chave que remetem a questões relacionadas à GSCM. Para uma melhor adequação aos estudos, e considerando que nos congressos escolhidos são publicados artigos em língua portuguesa e inglesa, as palavras-chave pesquisadas também seguiram essa orientação. Desta forma, os termos pesquisados foram cadeia de suprimentos verde (green supply chain), análise do ciclo de vida (life cicle analysis), ecodesign ou design ambiental (design for environment), logística reversa (reverse logistics) e outros relacionados com a GSCM. A escolha desses termos para proceder à busca retrospectiva nos anais dos eventos citados baseou-se na obra de Burgess et al. (2006) e Srivastava (2007). Esses termos podem ser vistos na Figura 2, extraída desse último autor.

Figura 2 - Classificação baseada no contexto dos problemas da GSCM 


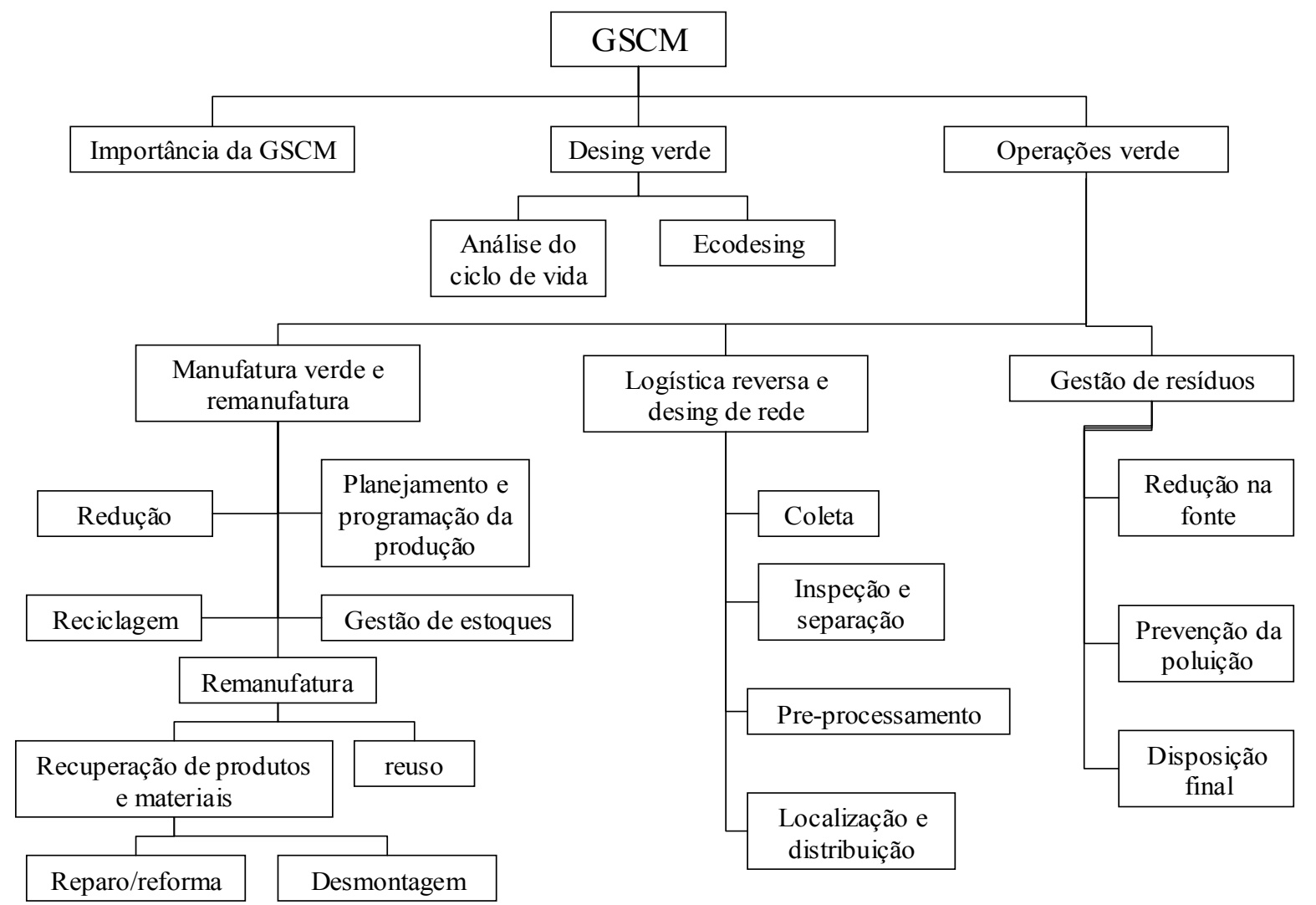

Fonte: Adaptado de Srivastava (2007, p. 57)

Após a coleta dos artigos, procedeu-se à análise dos dados levando em consideração categorias de análise pré-definidas baseadas nos trabalhos de Burgess et al. (2006) e Srivastava (2007). Desta forma, foram analisadas as seguintes categorias: (a) subárea em GSCM, (b) tipo de estudo (teórico ou empírico), (c) abordagem da pesquisa (qualitativa, quantitativa ou quali-quanti), (d) metodologia utilizada (estudos de caso, survey etc.), e (e) setor da economia. Vale ressaltar que tais categorias também foram escolhidas devido a seu potencial explicativo, o que apoiará posteriormente a análise dos dados. A seguir podem ser verificados os resultados da pesquisa.

\section{RESULTADOS E DISCUSSÃO}

Inicialmente foram coletados e analisados os artigos publicados nos anais de 2006 a 2010 anos de três dos principais congressos brasileiros das áreas de Administração e Engenharia de Produção. Conforme mostra o Gráfico 1, observou- 
se que no ano de 2006 foram publicados 20 artigos no SIMPOI, 17 artigos no SIMPEP e somente um artigo no EnANPAD. Em 2007, a maior parte das publicações, totalizando 13 artigos, foi encontrada no SIMPEP, o SIMPOI aceitou oito trabalhos e o EnANPAD não apresentou nenhuma publicação. Novamente em 2008, o EnANPAD não teve nenhum trabalho aceito, o SIMPEP apresentou dois artigos e o SIMPOI apresentou 16 trabalhos. Em 2009, observou-se nos três eventos uma redução na quantidade de trabalhos publicados, sendo apenas um artigo no EnANPAD, dois no SIMPOI e o SIMPEP não teve nenhum trabalho aceito. No ano de 2010, foram aceitos quatro artigos no EnANPAD, no SIMPEP foram apresentados 18 artigos e no SIMPOI oito artigos. Ao todo, considerando o período de 2006-2010, foram analisados seis artigos apresentados no EnANPAD, 50 no SIMPEP e 54 no SIMPOI.

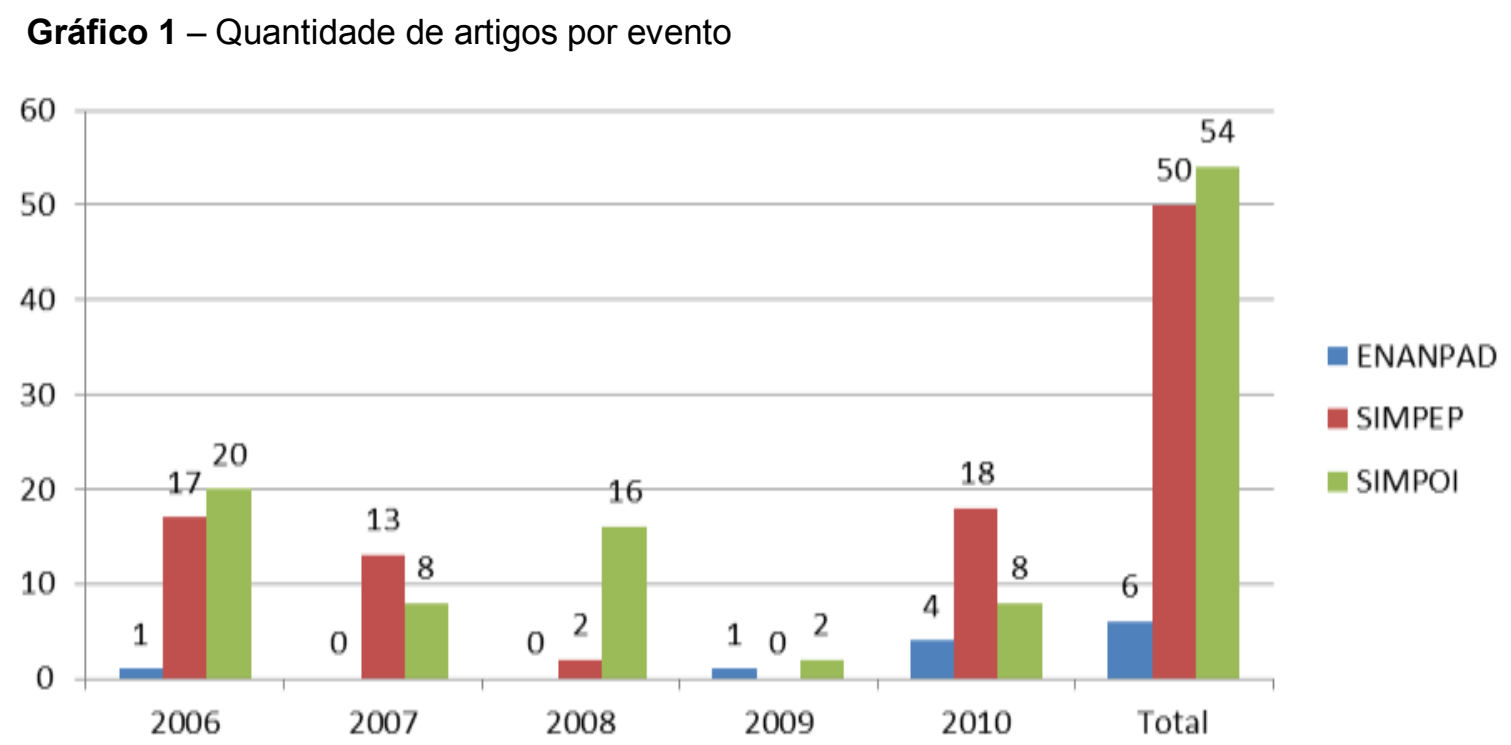

Fonte: Elaborado pelos autores

Chamou atenção a baixa quantidade de artigos publicados no ano de 2009, observando que houve uma redução considerável comparando-se com a quantidade de trabalhos publicados sobre GSCM no ano anterior. Porém, logo após, em 2010, a quantidade de artigos publicados voltou a crescer, inclusive no EnANPAD (quatro artigos), congresso que menos publicou artigos sobre o tema. A diferença na quantidade de artigos publicados no EnANPAD de um lado, e no SIMPOI e SIMPEP de outro, pode ser explicada pelo foco dos eventos. Esses dois últimos são eventos 
focados em Gestão de Operações, sendo talvez um ambiente mais propício para discussão e publicação em GSCM. Já o EnANPAD é um congresso mais abrangente e que contempla diversas áreas de pesquisa, ou seja, tem perfil bem diferente dos outros dois eventos cujos dados foram coletados. Além das diferenças, tais números demonstram também que o tema ainda é incipiente nos congressos brasileiros, apesar do destaque dado às temáticas relacionadas ao meio ambiente na mídia e na academia de Administração e Engenharia de Produção de uma forma geral.

Em seguida, foram analisados o tipo de estudo, a abordagem da pesquisa e a metodologia utilizada nos artigos coletados. Observou-se que $70,91 \%$ dos artigos eram empíricos e que os artigos teóricos totalizaram 29,09\%. Quanto à abordagem da pesquisa, $77,22 \%$ são de natureza qualitativa, $16,46 \%$ são quantitativos e $6,33 \%$ utilizaram uma abordagem quali-quanti. No que se refere à metodologia aplicada, observa-se que em $57,27 \%$ dos artigos o método empregado foi o estudo de caso. A revisão bibliográfica esteve presente em $29,09 \%$ dos trabalhos, as pesquisas do tipo survey totalizaram $5,45 \%$ dos artigos e pesquisas com dados secundários, $2,73 \%$. Os métodos experimentais e desk research foram utilizados em 1,82\% dos trabalhos cada um. Pesquisa ação e delphi apareceram em 0,91\% cada. Tais achados estão sintetizados no Gráfico 2 abaixo.

Gráfico 2 - Tipo de estudo, abordagem da pesquisa e metodologia

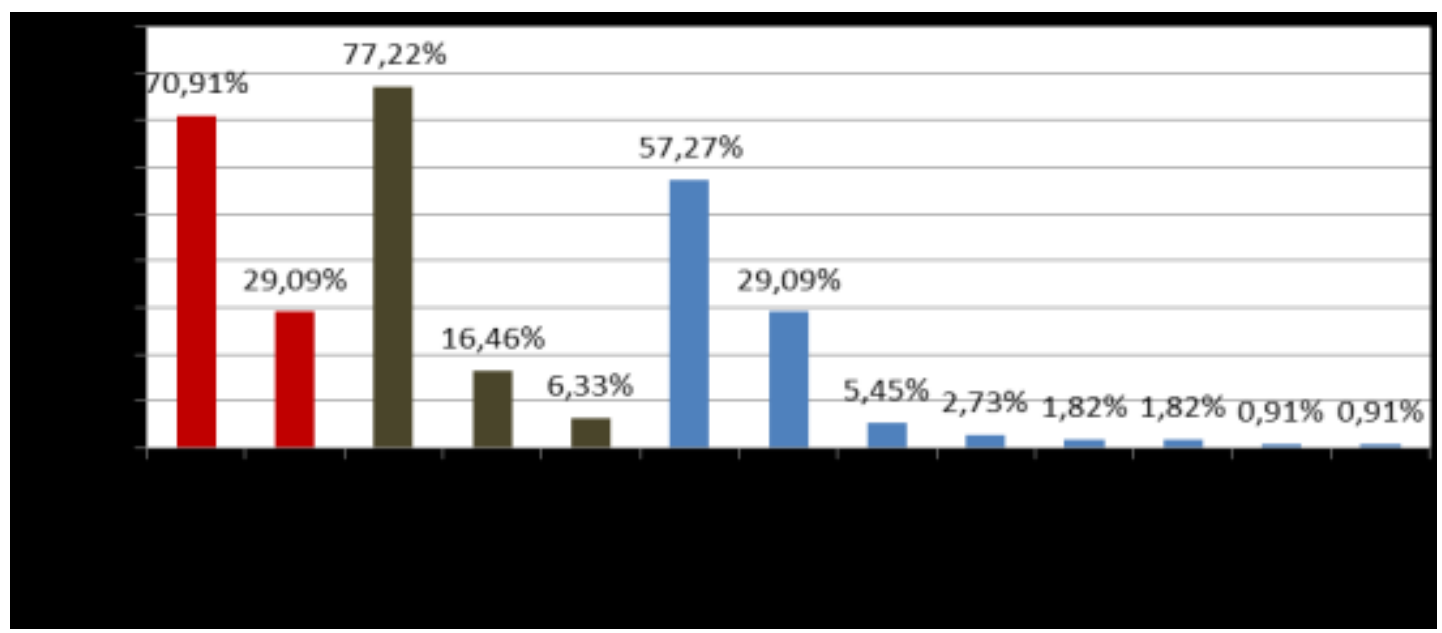

Fonte: Elaborado pelos autores 
No que tange ao tipo de pesquisa, os percentuais de $70,91 \%$ e $29,09 \%$ para estudos empíricos e teóricos, respectivamente, são coerentes com os números da Gestão de Operações, bem como de outras áreas da Administração; pode-se perceber resultado similar na pesquisa de Balestrin et al. (2010). Já no aspecto abordagem da pesquisa, os artigos publicados sobre GSCM nos congressos estudados têm perfil diferente da área de operações no contexto internacional, pois $77,2 \%$ são estudos qualitativos, enquanto no exterior a principal abordagem utilizada é quantitativa. Os motivos podem ser, por exemplo, falta de métricas (e escalas) validadas e confiáveis para empreender estudos quantitativos mais robustos, sendo este um próximo passo para o desenvolvimento do tema no Brasil. Além disso, de certa forma, o acesso a bancos de dados estruturados, e também a uma grande quantidade de empresas através de surveys, colaborou para o grande número de pesquisas quantitativas no exterior. No Brasil, a realidade de acesso ao campo empírico é diferente e mais difícil, talvez por isso a abordagem qualitativa seja mais utilizada, já que necessita de uma quantidade menor de empresas em cada estudo.

Isso pode ser corroborado a partir dos achados referentes à metodologia das pesquisas, que em sua maioria utilizou a técnica de estudo de caso qualitativo $(55,45 \%)$ e em bem menor escala o estudo de caso quantitativo $(1,82 \%)$, totalizando $57,27 \%$ de estudos de caso em GSCM. A utilização dessa metodologia reforça o status da GSCM enquanto campo de estudo ainda em fase exploratória e de consolidação de conceitos, já que se tenta avançar através de eventos individualizados. Além disso, o baixo volume de estudos quantitativos também pode significar que a GSCM ainda não faz parte da rotina de atividades das empresas brasileiras, e com isso existiriam poucos casos a serem examinados. Desta forma, pode-se constatar que, na área de GSCM, o estudo de caso tem sido a metodologia mais aplicada, em vez de estudos quantitativos robustos e com grandes amostras.

A GSCM, conforme mostrado na Figura 1, adaptada de Srivastava (2007), está dividida em dois níveis, e no primeiro nível tem-se a Importância da Gestão Verde da Cadeia de Suprimento (Importance of Green Supply Chain Management); o Design Verde (Green Design) e as Operações Verdes (Green Operations). Conforme mostra o Gráfico 3, dentre os artigos analisados, 81,82\% abordam Operações Verdes, $11,82 \%$ tratam da Importância da Gestão Verde da Cadeia de 
Suprimentos e 6,36\% relacionam-se com Design Verde. Tal observação pode sugerir que, no campo, a área mais estudada de 2006 a 2010 foi Operações Verdes. Contudo, em números absolutos, considera-se que não apresenta uma grande quantidade no período de cinco anos, um total de 89 artigos, o que reafirma o caráter neófito da GSCM nos estudos brasileiros.

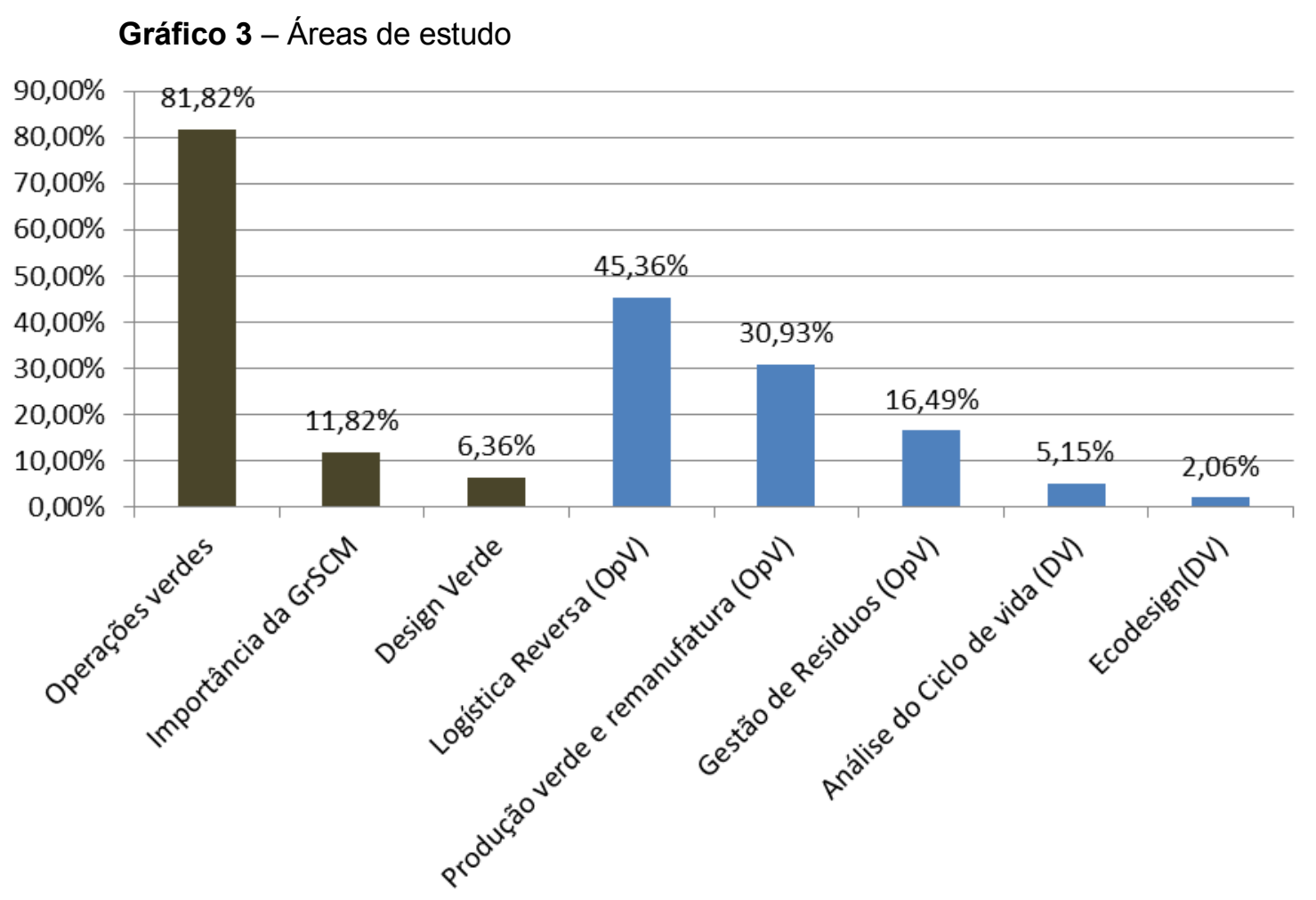

Fonte: Elaborado pelos autores

Ao analisar os subconceitos (segundo nível) de acordo com Srivastava (2007), Operações Verdes (OpV) se divide em Logística Reversa, Manufatura Verde e Remanufatura e Gestão de Resíduos; já o Design Verde (DV) se divide em Análise do Ciclo de Vida e Ecodesign. Conforme mostra o Gráfico 3, no âmbito das Operações Verdes, verificou-se a predominância da Logística Reversa em 45,36\% dos artigos analisados (destes, 5,36\% estão na categoria Importância da GrSCM), $30,93 \%$ estudaram a Manufatura Verde e Remanufatura, e 16,49\% trataram da questão da Gestão dos Resíduos. Quanto ao âmbito do Design Verde, 5,15\% abordaram a Análise do Ciclo de Vida e apenas 2,06\% pesquisaram sobre Ecodesign. 
Os resultados da pesquisa apontam a área de Operações Verdes como a mais significativa dentre aquelas propostas por Srivastava (2007). A área de Design Verde, que possui alto potencial de agregação de valor, apresenta um baixo volume de artigos e de discussão acadêmica entre os artigos coletados. Ainda sobre Design Verde, a maior parte dos trabalhos aborda a Análise do Ciclo de Vida, sendo raros os trabalhos que abordaram elementos de Ecodesign, o que pode representar um descompasso no que diz respeito à inovação em produtos sustentáveis.

Quanto aos setores pesquisados, observou-se que a GSCM foi estudada em uma quantidade pulverizada de indústrias, desta forma optou-se por agrupar tais indústrias em categorias, no intuito de uniformizar a análise. As indústrias estudadas nos artigos coletados foram agrupadas da seguinte forma: indústria de base (cimenteiro, madeireiro, mineração, papel e celulose, petróleo e gás, plástico, químico, siderurgia, sucroalcooleiro); bens de consumo duráveis (automobilístico, eletrodoméstico, eletrônico, gráfico, informática, moveleiro, remanufatura); bens de consumo não-duráveis (agricultura, alimentos, bebidas, coureiro, embalagens, farmacêutico); infraestrutura (construção civil, energia, transporte); serviços (ensino superior, hotelaria, saúde, serviços governamentais); comércio (varejo); e bens de capital (metal-mecânico). Conforme mostra o Gráfico 4, foram obtidos os seguintes resultados: Indústria de Base, 28,00\%; Bens de Consumo Duráveis, 21,33\%; Bens de Consumo Não-Duráveis, 17,33\%; Infraestrutura, 10,67\%; Serviços, 12,00\%; Comércio, 6,67\% e Bens de Capital, 4,00\%. Desta forma, pode-se observar que a maioria dos estudos empíricos concentra-se nas indústrias de base e de bens de consumo duráveis, totalizando quase metade $(49,33 \%)$ da totalidade das observações. Um aspecto que explica este achado é o uso intensivo de recursos naturais pelas indústrias de base e pelas indústrias de bens duráveis, o que justifica a escolha desses setores para pesquisas que envolvem o meio ambiente. 


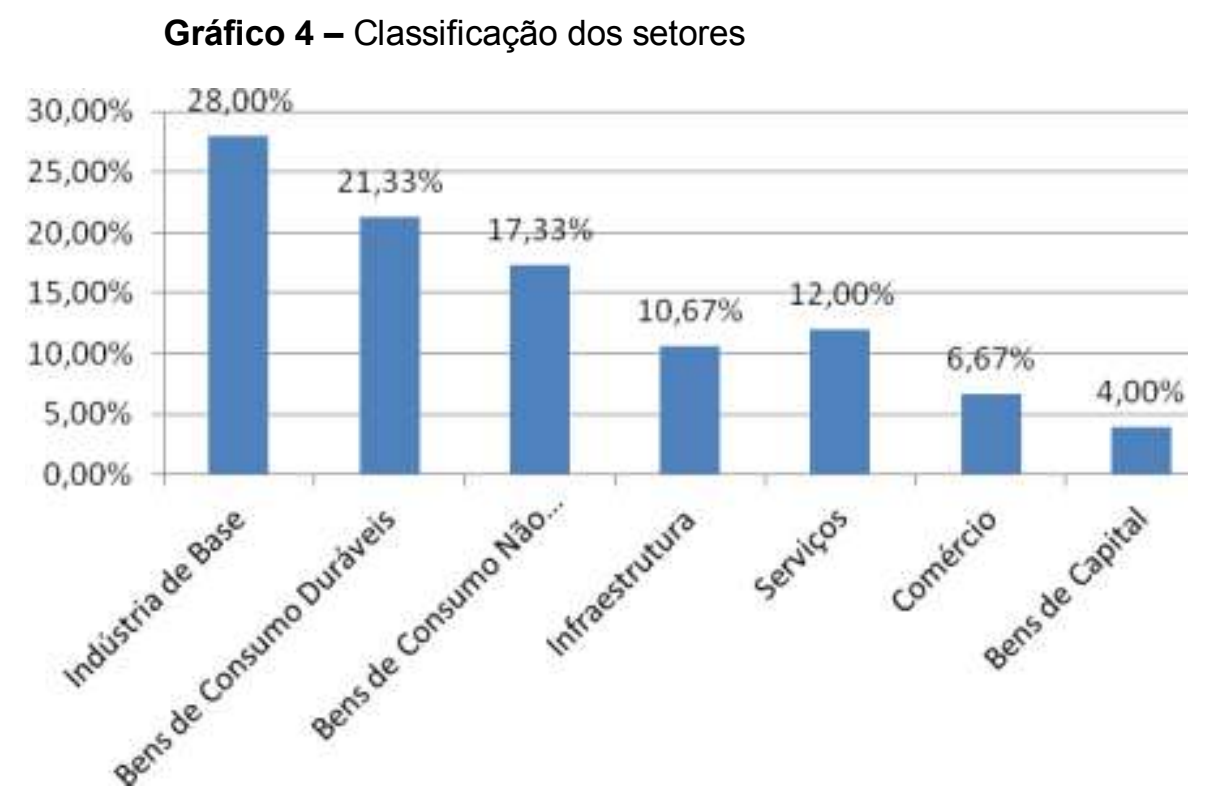

Fonte: Elaborado pelos autores

A Figura 3 representa, em cores, o resultado do presente estudo baseado no modelo de análise proposto por Srivastava (2007), onde se identificam as subdivisões da GSCM. A análise dos artigos aceitos nos congressos escolhidos permite pressupor que existe uma discussão sobre a Importância da Gestão Verde da Cadeia de Suprimentos (11,82\%), assim como Operações Verdes $(81,82 \%)$ e Design Verde (6,36\%). Contudo, este último apresenta níveis muito baixos, tanto no que tange à "análise do ciclo de vida" (5,15\%), mas principalmente no que se refere ao "ecodesign" (2,06\%).

Quanto às questões ligadas à subárea Manufatura Verde e Remanufatura, no âmbito das Operações Verdes, os estudos se concentram de forma muito intensa em assuntos ligados a "reciclagem", havendo ainda alguma produção que trate de "redução" e "remanufatura", e permanecendo a "gestão de estoques" e o "planejamento e programação da produção" fora da pauta de 2006 a 2010. Ainda no âmbito das Operações Verdes, no que se refere à subárea Logística Reversa, os aspectos de "coleta" e "localização e distribuição" já se encontram entre os temas discutidos, enquanto a "inspeção e separação" e o "pré-processamento" ainda constituem gaps teórico-empíricos por ausência de estudos sobre esses temas.

Finalmente, a subárea de Gestão de Resíduos é aquela que parece melhor coberta pelos artigos publicados, com trabalhos que tratam de todos os seus 
elementos, mesmo havendo uma predominância da discussão sobre "disposição final" em relação aos temas "redução na fonte" e "prevenção da poluição". Contudo, tais resultados levam a crer que ainda existe um predomínio de condutas que visam unicamente livrar-se do resíduo gerado, no âmbito de uma postura reativa de atendimento da legislação vigente, numa perspectiva de comando e controle (BARBIERI, 2007).

Ao utilizar o esquema classificatório da Figura 2 (SRIVASTAVA, 2007, p. 57) e aplicá-lo aos estudos brasileiros apresentados nos eventos científicos analisados, tem-se a Figura 3. Ao observar a Figura 3, pode-se constatar que cada área, subárea e tema específico está em cores diferentes, o que representa o atual estado das pesquisas. Em vermelho, estão as áreas mais críticas, onde foram encontrados poucos ou não foram encontrados estudos, sendo assim importante uma ampliação das pesquisas sobre esses aspectos. Em verde, estão as áreas nas quais foi encontrada a maioria dos trabalhos. Por fim, em amarelo, estão aquelas áreas que ficaram no meio termo.

Figura 3 - Classificação baseada nos problemas da GSCM dos artigos analisados

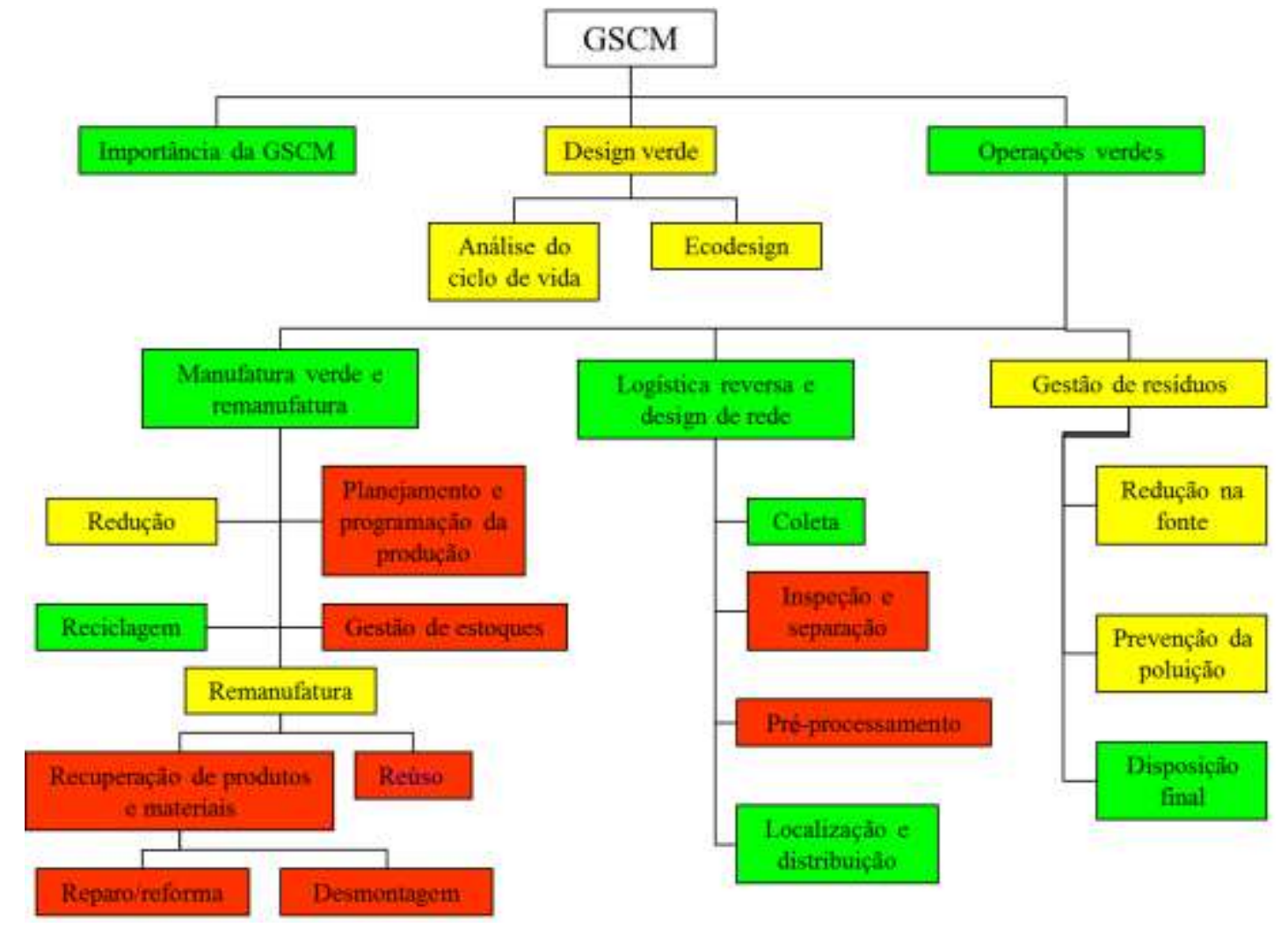

Fonte: Dados da pesquisa adaptados ao modelo de Srivastava (2007, p. 57)

Revista Produção Online, Florianópolis, SC, v.14, n. 3, p. 1104-1128, jul./set. 2014. 
Ao analisar todo o conjunto de artigos coletados, foram encontradas outras áreas de pesquisa que não estão contempladas no modelo de Srivastava (2007). Conforme mostrado no Gráfico 5, numa classificação de subáreas, assuntos como inovação em sustentabilidade, produção mais limpa $(P+L)$, mecanismos de desenvolvimento limpo (MDL) e eficiência energética foram encontrados nos trabalhos sobre GSCM, e tais temas não são contemplados diretamente pelo modelo de Srivastava (2007). Tal achado configura-se como uma contribuição à área de GSCM, pois demonstra que no Brasil uma futura e possível agenda de pesquisa para a área deve levar em consideração temáticas que façam sentido no âmbito das necessidades de conhecimento em GSCM do país.

Gráfico 5 - Classificação de novas subáreas encontradas

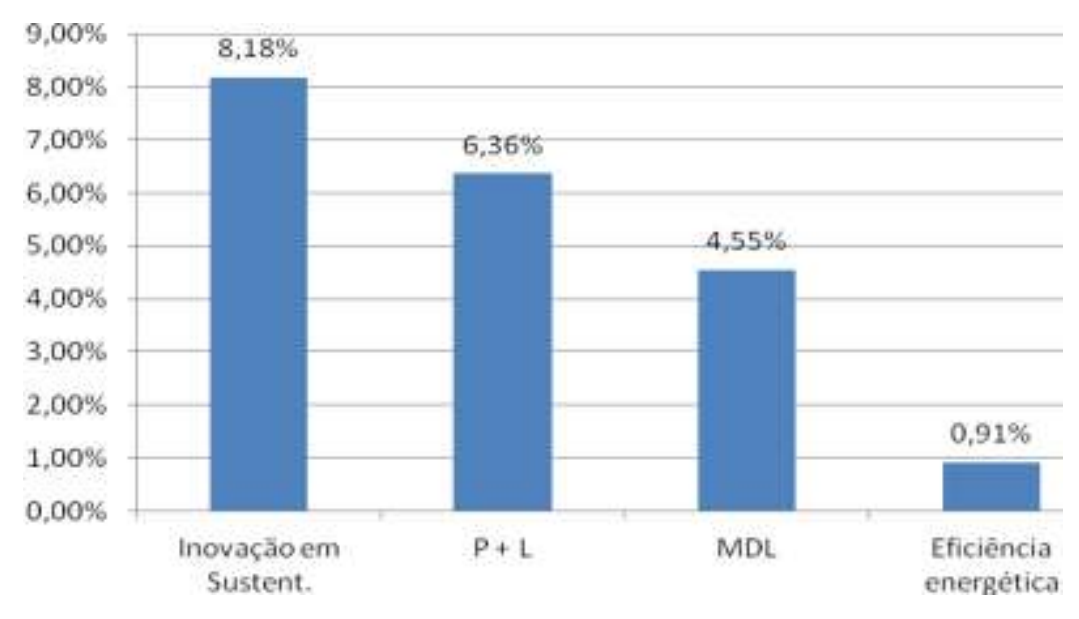

Fonte: Elaborado pelos autores

O tópico a seguir trata das considerações finais do artigo, buscando enfocar necessidades de pesquisa futura, limitações da presente pesquisa e contribuições deste trabalho para a área de Gestão Verde da Cadeia de Suprimentos.

\section{CONSIDERAÇÕES FINAIS}

O presente trabalho objetivou analisar a produção acadêmica brasileira sobre o tema Gestão Verde da Cadeia de Suprimentos. Para isso, foram seguidos os seguintes passos: (a) delimitação adequada do escopo da coleta de dados, visando 
coletar uma quantidade significativa de artigos no âmbito da gestão verde da cadeia de suprimentos; (b) categorização dos artigos em subáreas no âmbito da gestão verde da cadeia de suprimentos; e (c) verificação das abordagens, setores e aspectos metodológicos utilizados nos artigos encontrados.

Foram coletados e analisados os artigos publicados nos anais do EnANPAD, SIMPOI e SIMPEP nos anos de 2006 a 2010, perfazendo um total de 110. Como consequência, emergiram lacunas de pesquisa que podem ser preenchidas pelos pesquisadores da área de GSCM, já que tais lacunas são consideradas oportunidades para novos trabalhos e publicações. Assim, a análise da produção científica sobre a temática GSCM possibilitou algumas reflexões que demonstram a necessidade de novas pesquisas para esse campo de estudo. A proposição de novas pesquisas é necessária por dois motivos distintos, são eles: (a) o caráter neófito da área no Brasil, que no momento encontra-se em expansão e necessita de maiores estudos, e (b) a concentração de produção científica em algumas subáreas e a pouca, ou falta de, produção em outras.

A área de Operações Verdes foi a mais representativa, e a maioria dos trabalhos foram estudos de caso qualitativos. Apesar do maior volume de produção científica em Operações Verdes, existem temas que continuam inexplorados, ou seja, não foi encontrado nenhum artigo, a exemplo do "planejamento e programação da produção", "gestão de estoques", "recuperação de produtos e materiais", "reúso", "reparo/reforma", "desmontagem", todos no âmbito da Manufatura Verde e Remanufatura. Além desses, os temas "inspeção e separação" e "préprocessamento" no âmbito da Logística Reversa também ainda estão inexplorados. Vale ressaltar que a temática geral Logística Reversa deve ganhar importância no cenário nacional devido à aprovação da lei do Programa Nacional de Resíduos Sólidos (PNRS), que trouxe uma série de obrigações às empresas nesse sentido. A subárea Gestão de Resíduos apresentou poucos trabalhos, e a maioria deles se concentrou no tema "disposição final", sendo ainda menor a quantidade de trabalhos em "redução na fonte" e "prevenção da poluição".

Quanto à área de Design Verde, observou-se um baixo volume de produção científica, o que pode refletir a necessidade de aprofundamento no tema. Essa pouca quantidade de trabalhos, principalmente no que diz respeito ao "ecodesign", é 
coerente com as baixas quantidades de estudos sobre "redução na fonte" e "prevenção da poluição", pois em geral as práticas relacionadas com esses temas são as mesmas que estimulam as inovações que incorporam critérios ambientais, como é o caso do "ecodesign".

Desta forma, baseando-se nos achados e nas lacunas teóricas observadas, segue no Quadro 1 uma proposição para futuros estudos, no intuito de desenvolver as lacunas da área de GSCM no Brasil.

Quadro 1 - Proposição para estudos futuros

\begin{tabular}{|l|l|l|}
\hline Área & Subárea & Temas pouco ou não explorados \\
\hline \multirow{5}{*}{ Operações Verdes } & Manufatura verde e remanufatura & $\begin{array}{l}\text { Planejamento e programação da } \\
\text { produção }\end{array}$ \\
\cline { 2 - 3 } & Manufatura verde e remanufatura & Gestão de estoques \\
\cline { 2 - 3 } & Manufatura verde e remanufatura & Recuperação de produtos e materiais \\
\cline { 2 - 3 } & Manufatura verde e remanufatura & Reúso \\
\cline { 2 - 3 } & Manufatura verde e remanufatura & Reparo/reforma \\
\cline { 2 - 3 } & Logística reversa & Desmontagem \\
\cline { 2 - 3 } & Logística reversa & Pré-processamento \\
\cline { 2 - 3 } & Gestão de resíduos & Redução na fonte \\
\cline { 2 - 3 } & Gestão de resíduos & Prevenção da poluição \\
\hline \multirow{3}{*}{ Design Verde } & Análise do ciclo de vida & Temas diversos \\
\cline { 2 - 3 } & Ecodesign & \\
\hline
\end{tabular}

Fonte: Elaborado pelos autores

Tais proposições buscam preencher as lacunas observadas na produção científica da área de GSCM, cabendo ressaltar que tais lacunas se configuram como oportunidades de pesquisas e publicações futuras, bem como possibilidades de contribuição para o campo. A ocupação dessas lacunas é importante para a consolidação, crescimento e evolução da área de GSCM no Brasil, ampliando assim seu reconhecimento.

Como qualquer estudo acadêmico, este também possui limitações, dentre as quais podem ser citadas principalmente: (a) o tempo escolhido de coleta dos artigos (2006-2010), e (b) a quantidade de eventos analisados. Numa perspectiva de 
escopo, a decisão sobre tempo e quantidade foi tomada levando em consideração os recursos disponíveis, fato que foge do poder de intervenção dos pesquisadores. Contudo, tais limitações podem ser resolvidas em trabalhos futuros, conforme constam nas sugestões a seguir.

Como sugestão para pesquisas futuras, torna-se importante ressaltar os seguintes tópicos: (a) ampliação da base de análise a partir da coleta de artigos em anais de outros congressos como o Encontro Nacional de Engenharia de Produção (ENEGEP) e Encontro Internacional sobre Gestão Empresarial e Meio Ambiente (ENGEMA); (b) replicar o presente estudo em anos posteriores, buscando analisar a evolução do tema no Brasil; (c) empreender estudos em GSCM que possam contribuir para a evolução do conhecimento em âmbito internacional, levando em consideração o mainstream da área de operações.

\section{REFERÊNCIAS}

ANGELL, L. C.; KLASSEN, R. D. Integrating environmental issues into the mainstream: an agenda for research in operations management. Journal of Operations Management, v. 17, n. 5, p. 575-598, 1999.

http://dx.doi.org/10.1016/S0272-6963(99)00006-6

BALESTRIN, A; VERSHOORE, J.; REYES JUNIOR, E. O campo de estudo sobre redes de cooperação interorganizacional no Brasil. Revista de

Administração Contemporânea, v. 14, n. 3, p. 458-477, 2010. http://dx.doi.org/10.1590/S1415-65552010000300005

BARBIERI, J. C. Gestão ambiental empresarial: conceitos, modelos e instrumentos. São Paulo: Saraiva, 2007.

BURGESS, K.; SINGH, P. J.; KOROGLU, R. Supply chain management: a structured literature review and implications for future research. International Journal of operations and Production Management, v. 26, n. 7, p. 703-729, 2006. http://dx.doi.org/10.1108/01443570610672202

CARVALHO, A.; BARBIERI, J. C. Sustentabilidade e gestão da cadeia de suprimento: conceitos e exemplos. In: VILELA JUNIOR, A.; DEMAJOROVIC, J. Modelos e ferramentas de gestão ambiental: desafios e perspectivas para as organizações. 2ed. São Paulo: SENAC, 2010.

CHOPRA, S.; MEINDL, P. Gerenciamento da cadeia de suprimentos: estratégia, planejamento e operação. São Paulo: Prentice-Hall, 2003. 
CORREAA, H. L. Gestão de redes de suprimentos: integrando cadeias de suprimento no mundo globalizado. São Paulo: Atlas, 2010.

GOLD, S.; SEURING, S.; BESKE, P. Sustainable supply chain management and inter-organizational resources: a literature review. Corporate Social Responsibility and Environmental Management, v. 17, p. 230-245, 2010.

GONÇALVES-DIAS, S. L. F.; LABEGALINI, L.; POLIDÓRIO, G. R. S. Sustentabilidade na cadeia de suprimentos: uma perspectiva comparada de publicações nacionais e internacionais. Anais do XXXIII Encontro Anual da Associação Nacional de Pós-graduação e Pesquisa em Administração. São Paulo: Anais do XXXIII EnANPAD, 2009.

HANSEN, A. P.; SEO, E. S. M.; KULAY, L. A. Identificação de oportunidades de melhoria de desempenho ambiental em processo de produção de materiais cerâmicos via aplicação da técnica de avaliação de ciclo de vida ( $A C V)$.

Revista Produção Online, v.10, n.4, p. 912-936, 2010.

http://dx.doi.org/10.14488/1676-1901.v10i4.526

HART, S. A natural-resource-based view of the firm. Academy of Management Review, v. 20, n. 4, p. 986-1014, 1995.

http://dx.doi.org/10.2307/258963

JACOBS, B. W.; SINGHAL, V. R.; SUBRAMANIAN, R. An empirical

investigation of environmental performance and the market value of the firm. Journal of Operations Management, v. 28, p. 430-441, 2010.

http://dx.doi.org/10.1016/j.jom.2010.01.001

JIMÉNEZ, J. B.; LORENTE, J. J. C. Environmental performance as an operations objective. International Journal of Operations and Production Management, v. 21, n. 12, p. 1553-1572, 2001.

http://dx.doi.org/10.1108/01443570110410900

KLASSEN, R. D.; VACHON, S. Collaboration and evaluation in the supply chain: the impact on plant-level environmental investment. Production and Operations Management, v. 12, n. 3, p. 336-352, 2003.

http://dx.doi.org/10.1111/j.1937-5956.2003.tb00207.x

KLEINDORFER, P. R.; SINGHAL, K.; WASSENHOVE, L. N. V. Sustainable operations management. Production and Operations Management, v. 14, $\mathrm{n}$. 4, p. 482-492, 2005.

http://dx.doi.org/10.1111/j.1937-5956.2005.tb00235.x

LAMBERT, D. M.; STOCK, J. R.; ELLRAM, L.M. Fundamentals of logistics management. New York: McGraw-Hill, 1998.

LINTON, J. D.; KLASSEN, R. D.; JAYARAMAN, V. Sustainable supply chains: an introduction. Journal of Operations Management, v. 25, p. 1075-1082, 2007. http://dx.doi.org/10.1016/j.jom.2007.01.012 
MAGNAGO, P. F.; AGUIAR, J. P. O; PAULA, I. C. Sustentabilidade em desenvolvimento de produtos: uma proposta para a classificação de abordagens. Revista Produção Online, v.12, n.2, p. 351-376, 2012.

MATOS, S.; HALL, J. Integrating sustainable development in supply chain: the case of life cycle assessment in oil and gas and agricultural biotechnology.

Journal of Operations Management, v. 25, p. 1083-1102, 2007.

http://dx.doi.org/10.14488/1676-1901.v12i2.796

MENTZER, J. et al. Defining supply chain management. Journal of Business Logistics, v. 22, n. 2, p. 4, 2001.

http://dx.doi.org/10.1002/j.2158-1592.2001.tb00001.x

PAGELL, M.; WU, Z. Building a more complete theory of sustainable supply chain management using case studies of 10 exemplars. Journal of Supply Chain Management, v. 45, n. 2, p. 37-56, 2009.

http://dx.doi.org/10.1111/j.1745-493X.2009.03162.x

PORTER, M. E.; VAN DER LINDE, C. Green and competitive: ending the stalemate. Harvard Business Review, v. 73, n. 5, p. 120-134, SeptemberOctober, 1995.

SELLITTO, M. A.; BORCHARDT, M.; PEREIRA, G. M.; PACHECO, D. A. J. Gestão de cadeias de suprimentos verdes: um quadro de trabalhos. Revista Produção Online, v.13, n.1, p. 351-374, 2013. http://dx.doi.org/10.14488/16761901.v13i1.1181

SEURING, S.; MULLER, M. From a literature review to a conceptual framework for sustainable supply chain management. Journal of Clean Development, v. 16, p. 1699, 2008. http://dx.doi.org/10.1016/j.jclepro.2008.04.020

SHARMA, S.; VREDENBURG, H. Proactive corporate environmental strategy and the development of competitively valuable organizational capabilities.

Strategic Management Journal, v. 19, p. 729-753, 1998.

http://dx.doi.org/10.1002/(SICl)1097-0266(199808)19:8<729::AIDSMJ967>3.3.CO;2-W

SILVA, L. A. A.; PIMENTA, H. C. D.; CAMPOS, L. M. S. Logística reversa dos resíduos eletrônicos do setor de informática: realidade, perspectivas e desafios na cidade do Natal-RN. Revista Produção Online, v.13, n.2, p. 544-576, 2013. http://dx.doi.org/10.14488/1676-1901.v13i2.1133

SRIVASTAVA, S. K. Green supply-chain management: a state-of-the-art literature review. International Journal of Management Reviews, v. 9, n. 1, p. 53-80, 2007. http://dx.doi.org/10.1111/j.1468-2370.2007.00202.x 
TESTA, F.; IRALDO, F. Shadows and lights of GSCM (green supply chain management): determinants and effects of these practices based on a multinational study. Journal of Cleaner Production, v. 18, p. 953-962, 2010. http://dx.doi.org/10.1016/j.jclepro.2010.03.005

VENDRAMETTO, O.; PALMERI, N.; NETO, G. C. O.; PERRETI, O. D. Cleaner production: a growing movement in Brazilian companies. Revista Produção Online, v.10, n.1, p. 49-70, 2010. http://dx.doi.org/10.14488/16761901.v10i1.240

WU, Z.; PAGELL, M. Balancing priorities: decision-making in sustainable supply chain management. Journal of Operations Management, v. 29, n. 6, p. 577590, 2011.

http://dx.doi.org/10.1016/j.jom.2010.10.001

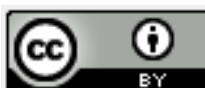

Artigo recebido em 12/09/2013 e aceito para publicação em 14/04/2014 DOI: http://dx.doi.org/ 10.14488/1676-1901.v14i3.1674 